\title{
BLAGA ȘI CIORAN - TRAGEDIA CULTURILOR MICI
}

\section{ALEXANDRA OLTEAN}

\section{Universitatea „Alexandru Ioan Cuza” din Iași}

Abstract: This paper aims to explain the affinities and differences of vision between Lucian Blaga and Emil Cioran on the phenomenon of Romanian historical evolution and national conscience. The two main works analyzed, The Mioritic Space and The Transfiguration of Romania, are in a passionate dialog, complementing each other in a conceptual and philosophical manner. The influence of Spengler's philosophy is fervent in the works of the two authors, but it is subject to a strong resemantization process in terms of the dynamics between large and small cultures. The place of Romanian culture and history will be presented empathically pozitive by Lucian Blaga, who will use will use it as a foundation for the picturesque theory of the stylistic array. On the other hand, Emil Cioran will condemn the psychological deficiencies of Romanian culture, incapable of creating history.

Keywords: history, conscience, national, culture, philosophy.

Fenomenul conștiinței românești și, implicit, cel al istoricității, devenite obiecte predilecte de reflecție pentru doi dintre cei mai proeminenți gânditori ai Interbelicului, Lucian Blaga și Emil Cioran, comportau cadre filosofice divergente, care însă nu excludeau un rodnic dialog al ideilor. Cele două lucrări semnificative, Spațiul mioritic și Schimbarea la față a României, deși au fost scrise în aceeași perioadă și publicate în același an, în decembrie 1936, au creat o remarcabilă efervescență ideatică printre cercurile intelectualității românești, reprezentând atitudini filosofice antinomice. Pilonii conceptuali pe care se fundamentează teoriile lui Lucian Blaga, „matricea stilistică” și celebrul „spațiu mioritic”, evoluează către avansarea ipotezei „boicotului istoric”, adică spre o ieșire din istorie, explicând particularitățile trecutului național. Emil Cioran contracarează 
o atare viziune idealistă, lansând, „cu pasiune și orgoliu”, un unghi demisionar și anatemizant față de presupusa măreție proceselor istorice care au amprentat spațiul românesc, infinit inferior marilor civilizații, caracterizate de o intimidantă forță individualizantă și de o corespondență intimă superioară între toate planurile civilizaționale. Totuși, aceste două dimensiuni contradictorii ale orizontului filosofic care circumscrie fizionomia spiritualității românești din pragul celei de-a doua conflagrații mondiale nu prezintă doar discordanțe ideatice ci, în mod surprinzător, ele conțin și o serie pasionantă de alinieri concordatare, completându-se într-o reciprocitate ce face, într-o oarecare măsură, apologia concilierii ireconciliabilelor.

Inexistenta înrudire temperamentală și incontestabila stridență a disensiunii metafizice trasează câteva direcții de armonizare, în ciuda evidențelor unui schimb de replici caustic la nivelul opticii teoretice. Desfășurările argumentative prezente în fiecare dintre cele două volume acționează, preponderent, în vederea anihilării opiniei oponente, reflectând consecvența sistemului blagian și a non-sistemului cioranian. Scriitorii mai aveau să fie apropiați prin magnitudinea realizărilor lor literare, filosofice și prin solidaritatea intelectuală specifică strălucitei lor generații, însă vor fi separați tranșant de mișcările nefaste ale istoriei și de imixtiunea totalitarismului. Desigur, revendicările de la tradiții filosofice distincte joacă și ele un rol esențial în configurarea duelului ideatic Blaga - Cioran asupra sigiliilor spiritualității și istoricității românești. Dinamica relațiilor dintre cei doi gânditori este ea înseși ambivalentă, natura interacțiunilor lor aflându-se sub semnul unor oscilante condiționări subiective și obiective. Mai tânărul Cioran manifestase efuziuni elogioase la adresa reușitelor filosofice prin care se remarcase Lucian Blaga în peisajul culturii românești. Apariția Eonului dogmatic, prima secvență din răsunătoarea operă cu miză epistemologică, Trilogia cunoașterii, prilejuise

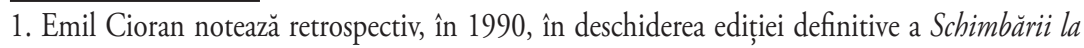
față a României: „Am scris aceste divagații in 1935-36, la 24 de ani, cu pasiune şi orgoliu. Din tot ce-am publicat în româneşte şi franţuzeşte, acest text este poate cel mai pasionat şi în acelaşi timp îmi este cel mai străin. Nu mă regăsesc în el, deşi îmi pare evidentă prezența isteriei mele de atunci. Am crezut de datoria mea să suprim cîteva pagini pretenţioase şi stupide. Această ediţ̧ie este definitivă. Nimeni nu are dreptul s-o modifce". Rafinamentul stilistic, inciziile aforistice și conținuturile ideatice sunt, paradoxal, asumate și reprimate, într-un joc histrionic ce nu dezminte personalitatea autorului lor, pregătit în orice moment să declame vicierea pozițiilor sale juvenile ori mature. 
un prim moment de consonanță între cele două viziuni ${ }^{2}$. Scepticul de la Rășinari apreciase finețea și capacitatea de pătrundere a teoriilor blagiene, încununând incursiunile pe teritoriul filosofiei lui Blaga $\mathrm{cu}$ articolul Stilul interior al lui Lucian Blaga, publicat în "Gândirea” în 1931, unde sublinia ignorarea structurilor rigide ale raționalismului, care deriva din „incapacitatea intelectului de a transforma misterul în non-mister”, afișânduși totodată și reticențele în ceea ce privește noțiunile în jurul cărora se cristalizează elanurile iraționaliste. Amândoi erau ardeleni ${ }^{3}$, captivați de spiritul filosofiei germane care oferea, de altfel, numeroase alternative filosofice.

$\mathrm{Cu}$ ocazia apariției celei de-a treia părți din Trilogia Cunoașterii, Cenzura transcendentă, Cioran însuși își exprimă nețărmuita admirație față de sistemul epistemologic blagian printr-o epistolă ce datează din 1934, cu doi ani înainte de statuarea celor două poziții filosofice asupra devenirii românești. Cu o căldură și simpatie destul de dificil de asociat cu faima sa de voce a diatribelor universale, eseistul din Rășinari se lasă pradă unor avânturi confesive atipice chiar asupra propriilor capacități de a inova domeniul gândirii cu reflecții de o originalitate incontestabilă: „această carte, care pentru mine n-are importanță numai prin faptul că e adâncă, fecundă și revelatoare, ci și prin aceea că mi-a descoperit cât de puțin sunt filosof. Assa încât, citind această carte, bucuria pentru idei atât de noi se tulbură de melancolia pierderilor mele proprii. Nu pot să devin filosof sau mai bine zis, nu sunt, fiindcă nu sunt și stăpân pe propriile mele idei"'t.

2. Emil Cioran vedea în Lucian Blaga expresia originalității gândirii românești, „o expresie atât de remarcabilă încât transcende infinit spiritul unei provincii", una dintre figurile notabile despre care se discută în scrierile sale publicistice, adunate ulterior în volumul Singurătate și destin.

3. Tot Emil Cioran oferă, în scrierile sale de tinerețe, un profil al psihologiei ardelenești, categorie care circumscrie și eclectismul intelectual manifestat de Lucian Blaga. Colecția de texte care compun Sfârșitul care începe (1994) explică proporțiile pe care alura spiritualității ardelenești le dobândiseră în conștiința gânditorului.

4. Apariția piesei de teatru Avram Iancu este semnalată encomiastic de Cioran într-o scrisoare din 1935 către autor tot ca o reușită dramaturgică demnă de numele lui Blaga, una dintre singurele sensibilități capabile să redea cromatica și sonoritatea gravă specifică unui trecut tragic: „Că ați ales din toată istoria românească figura cea mai tragică, veți înțelege, acesta este un motiv in plus de admirație. In sfârșit, avem opera care să ne facă actuală și sensibilă tristețea unui trecut, pe care a-l ințelege numai este o dramă. Avram Iancu așteaptă un compozitor care să-i dea accente tragice de Boris Godunov. Citind Avram Iancu, auzeam vag și indepărtat acordurile unei muzici subterane". 
Recunoașterea inconsistenței sclipirilor sale metafizice, fascinaţia pe care o exercită teoriile lui Blaga asupra sa și plasarea într-un raport de inferioritate față de gânditorul din Lancrăm indică posibila existență a unor apropieri la nivel conceptual. Rigurozitatea demonstrațiilor, aplicarea metodică și dozajul clar al ideilor, specifice caracterului sistemic al filosofiei blagiene, cadențau aspirațiile și frustările apologetului disperării. Reverberațiile acordurilor dintre convingerile filosofice ale celor doi scriitori vor continua să se propage, drept dovadă stând exercițiile eseistice de dată recentă publicate de Emil Cioran în volumul Exerciții de admirație, unde conștiința istorică este definită ca reflexie a ideii de providență, construct psihologic imposibil de eludat: „A atribui procesului istoric o semnificaţie, fie şi derivind-o dintr-o logică imanentă devenirii, inseamnă a subscrie, mai mult sau mai puţin explicit, la o formă de providenţă" (Cioran, 2002: 14). Sensurile conferite dinamicii istorice derivă, așadar, dintr-o conformație spirituală ce nu poate exclude formele autorității transcendente, imposibil de închis în formule definitive, „fără rest”.

Cioran își articulase principalele axe metafizice în jurul nucleelor conceptuale "tari”, avansate de Nietzsche și popularizate entuziast de trăirismul lui Nae Ionescu, insistând mizantropic asupra defectelor înscrise în fibra românească, în timp ce Lucian Blaga se revendica de la adaptarea dualismului lui Klages, format din dihotomia spirit-viață, şi argumenta în favoarea devenirii istorice autohtone referindu-se la vitregiile itinerariului trecutului românesc. Ionel Necula urmărește fibra înrâuririlor celor două opțiuni teoretico-filosofice, arătând că acestea nu se situau într-o opoziție de neîmpăcat și că lui Emil Cioran „i-ar fi plăcut să vadă că Blaga își extrage esența iraționalistă a viziunii sale din trăirea extatică și din exultanțele Sinelui, dornic să-și optimizeze resursele vitale și să crediteze o concepție despre lume" (Necula, 1995: 75), semn că afinitățile de perspectivă nu pot fi catalogate drept ipoteze hazardate, ci au un fundament real. Raportul beneficiază însă și de un revers, vădind mutualitatea reacțiilor celor doi filosofi. Lucian Blaga se va pronunța asupra judecăților emise de Cioran în chestiunea conștiinței românești, contestând existența unei viziuni personale, asumate. Gânditorul din Lancrăm observă, într-o scrisoare adresată lui Mircea Eliade, că, în ciuda seducătoarelor erupții ale paradoxului așezate într-un înveliș stilizat, "pesimismul său, cât privește cultura românească, rezultă din judecarea acesteia prin criterii absolut spengleriene. Adamismul e o conceptie care nu rezistă, și cred că după spațiul mioritic nu va mai putea susține nimeni teza despre arderea etapelor. Antiintelectualismul si provitalismul lui Cioran 
(sunt, ad.n) în întregime Klages. [...] Cioran se va astâmpăra peste vreo câțiva ani, când va ajunge, sunt sigur, la o viziune personală" (Blaga, 1989: 286). Anii întunecați care s-au succedat de la instaurarea comunismului și până la moartea lui Lucian Blaga în 1961 au aruncat cele două personalități în contexte sociale și intelectuale contrastante, care vor conduce la degradarea legăturilor lor.

Singurul compromis realizat de Lucian Blaga sub presiunea veninoaselor directive impuse de liniile autorităţii oficiale a fost redactarea unui articol denigrator despre Ispitei de a exista. Lectura acestui volum s-a transformat într-un atac orientat cu stângăcie către autor. Atacând originalitatea unui "depresiv grandilocvent care se complace intr-un univers contaminat de haos" (Sasu, 2016: 306), contribuția metafizică a scriitorului ce se refugiase pe malurile Senei este așezată între paranteze și etichetată drept produs al unei scandaloase afecțiuni intelectuale, intitulată ,amnezie a ghilimelelor". Anarhia intelectuală, mimetismul, mizantropia și atitudinea resentimentară față de propria țară se conjugă, în cadrul textului blagian silit de împrejurări, cu formulări-standard, de un naționalism forțat, fiind inimaginabil de asociat cu numele filosofului. Decalajul dintre poziția cunoscută a autorului și conținut frapează. Articolul, care a fost publicat postum în "Contemporanul” în 1962, se încheie ironizând și condamnând fascismul pe care Cioran, aflat sub influența lui Nietzsche, l-ar idolatriza.

Răspunsul victimei nu va întârzia să apară, discret, în însemnările adunate sub coperta Caietelor cioraniene, publicte tot postum. Când Emil Cioran află că gânditorul pe care îl prețuia mai presus de oricine și-a pervertit înaltele principii, el constată cu dezamăgire că structura etică admirată se dovedește surprinzător de flexibilă și notează, cu verva caracteristică: "Îl pusesem pe L. Blaga pe un piedestal (ca să vorbesc ca servitoarele), credeam că este mai presus de noi, că plutește, nepăsător san meditativ, străin de certurile noastre, incapabil de reacții balcanice, de hachițe sau de accese de invidie. [...] Vai, zeul s-a prăbușit! Poate că-i mai bine așa. Iată-l la fel ca noi toți (dar a murit, sărmanul!), iată-l uman și demn de dispreț". (Cioran, 2016, 118). Orgoliul eseistului este inflamat de înșiruirea de acuzații care pigmentează articolul lui Blaga, cu atât mai mult cu cât îi confirmă totodată și intuițiile sumbre privitoare la condiția umană, dezamăgitoare în esența sa. Cioran se precipită să arunce și el o ultimă săgeată spre idol, despărțindu-se definitiv de umbra sa, relativizantă ca efect existențial: „Dar paginile acre și de o răutate atât de penibilă pe care le-a scris despre mine și care-au fost găsite printre hârtiile lui, acum, la doi 
sau trei ani după moarte, au un aer de testament, de insultă de dincolo de mormânt - ce mă împiedică să fiu atât de obiectiv pe cât ar trebui" (Cioran, 2016, 118). Accidentul biografic ce pune pecetea adversității pe relațiile celor doi devine emblematic deoarece se datorează exclusiv dinamicii istorice și circumstanțelor politice, nefiind ocazionat de o ciocnire de ordin teoretic ori principial. Blaga nu va mai avea ocazia să-și rectifice poziția sau să se justifice în fața lui Cioran și a culturii române, în ciuda conduitei intelectual-etice admirabile menținute în anii de după cel de-al Doilea Război Mondial până la cedarea în fața presiunilor oficialităților comuniste.

Spațiul mioritic și Schimbarea la față a României vor dezbate cu aplomb polemic, înainte de acest eveniment nefericit, cristalizarea și evoluția spiritului românesc de pe două poziții filosofice aparent de neîmpăcat. Idealismul organicist-pitoresc blagian și luciditatea incisivă, amprentă a scepticismului cioranian, își găsesc o graniță comună în circumscrierea statutului culturii române în dinamica istorică. La acest prim consens, fiecare dintre cei doi gânditori își imprimă propriile nuclee de sens, aplicând resemantizări conforme cu viziunile deja încetățenite. Dihotomia cultură mare sau majoră și cultură mică sau minoră reprexintă o axă comună celor două discursuri, asemenea situării spațiului românesc în ultima categorie. Nuanțele tratării acestei chestiuni integratoare variază, întrucât Lucian Blaga nu așază cele două tipuri de culturi într-un raport antinomic, grefat pe opoziția terminologică de superior și inferior, ci descrie particularitățile fiecăreia prin corelarea cu formele specifice de organizare civilizațională și cu maniera de raportare la procesele istoriei, dirijate de mecanica evolutivă în tiparele căreia se înscrie fiecare cultură. Cultura majoră se distinge prin caracterul urban, prin racordarea la ritmurile modernității, în timp ce cultura minoră este exclusiv sătească, predilecția către ruralism atrăgând și „boicotul istoric”, o situare în afara vâltorilor produse de procesele istorice. Perspectiva organicistă asupra formării culturii române, așezată în deplină comuniune cu categoriile spațiale și temporale este de sorginte spengleriană. Acest morfologism culturalistoric asumat și de Lucian Blaga prin lectura scrierilor lui Leo Frobenius și Oswald Spengler izvorăște din viziunea lui Goethe despre individ și viață. În studiul intitulat "Formarea și transformarea fințtelor organice", poetul german vorbește despre diversitatea și multiplicitatea formelor de existență, independente și unice. Secolul romantic a impulsionat vizibil această perpetuă căutare a începuturilor, preocuparea pentru geneza fenomenelor conferind filosofiei istoriei un avânt extraordinar, ale cărui 
ecouri au continuat să se răspândească de-a lungul epocilor.

Fizionomia istorică a spațiului românesc nu se pliază pe șabloanele propuse de definiițiile filosofice, ce privesc strict dimensiunea temporală din unghi supraindividual, dovedindu-se incomplete și firave în fața scrutărilor unei conștiințe critice. Lucian Blaga decide să nuanțeze statutul românilor în centrul vastului repertoriu de secvențe ale trecutului, relaționând evaziunea lor din istorie cu retragerea romanilor din Dacia, eveniment ce declanșează nu o involuție sau un refuz al progresului, ci un alt tip de dezvoltare culturală: „In Dacia Traiană situația prezenta sub toate aspectele condiţii optime pentru injghebarea şi declanşarea unei «istorii» de viguroasă linie interioară, fie în cadrul imperiului, fie independent de imperiu. Dar au venit năvălirile, aşa-zise barbare, care mai întâi au zguduit şi pe urmă au distrus cadrul acestor posibilități de istorie, inceputurile românismului coincid astfel cu o "retragere» din «istorie», şi din toate posibilitățile ei ritmice şi dialectice, într-o viaţă nu lipsită de cultură, nu despuiată de forme, dar anistorică. Pentru câteva veacuri viaţa pre-românească şi apoi românească a fost nevoită, sub presiuneaevenimentelor ce se desfăşurau fulgerător pe drumurile şi in văzduhul Daciei, să renunţe la «istorie», să se retragă adică într-o existenţă organică-sufletească, oarecum atemporală" (Blaga, 1969: 226). Retragerea din istorie determină coagularea unei entități etnice organice ce se distinge de parcursul celorlalte civilizații europene. Acest paralelism între existența culturii minore și istorie, sinonimă cu „întoarcerea în preistorie”, revine ca refren axiologic nu doar în scrierile filosofice, ci și în operele literare, romanul Luntrea lui Caron oferind câteva dintre cele mai sugestive ipostazieri ale mărcilor culturii românești, minore prin refractaritatea sa la zbaterile actualității: „Eram încercat de simțământul acut că "istoria», întruchipată în bombardiere imaginare, ne alunga spre "preistorie», spre o preistorie multimilenară simbolizată de ciobănia din preajmă” (Blaga, 2013: 12). Firul istoricității se desfășoară inegal pe calapodul culturilor mici și devine pentru acestea elementul esențial, antologic, criptic al realității, constituind fundamentul tuturor evenimentelor care le animă existența. Anacronismul apare drept seva din care își extrag manifestările spirituale exponeții spațiului românesc, aspect evidențiat și de autorul Schimbării la față a României, care nu ezită să articuleze peiorativ absența imboldului de a face istorie, fixată în codul genetic al culturii autohtone.

Remarcăm identitatea de fond asupra clivajului destinial care scindează itinerariul existențial românesc de cel al marilor culturi în glosările celor doi filosofi pe marginea proiecțiilor istoriei. Ambii gânditori cunoșteau 
teoriile spengleriene despre simțul istoric și morfologia manifestărilor culturale, la care se refereau frecvent în demonstrațiile lor. Oswald Spengler este artizanul ideii conform căreia istoria umanității evoluate se concretizează sub forma marilor culturi, dând exemplul Europei Occidentale. Simbolul spațial, cel temporal, particulare pentru fiecare cultură și elemente care subliniază caracterul individual al fiecăreia, devin premisele posibilității extraordinare de a crea istorie, adică un șir de evenimente unice, irepetabile și ireversibile, așa cum semnalează în Declinul Occidentului: "Numai popoarele istorice, adică cele care au o existență participativă la istoria universală, sunt și națiuni" (Spengler, 1996: 201,vol II). Denumirea de națiune se aplică, așadar, culturilor majore, condițiție ce se regăsește și la Emil Cioran 5 . Urmând acest raționamet, Spengler dezbate ideea unei istorii universale, care ar presupune ca toate culturile să beneficieze, în fiecare dintre stadiile lor evolutive, de aceleași potențialități și resurse de a se exprima, patentând teoria unei sume de istorii particulare. Însuși spiritul uman contrazice o viziune generalizatoare asupra sa și asupra devenirii unei civilizații deoarece „omul creativ a părăsit uniunea cu natura, îndepărtându-se cu fiecare nouă creație, tot mai mult și mai ostil de ea. A sa "istorie universală» este istoria unei separații fatale, care se adânceste continuu, între lumea oamenilor și univers" (Spengler, 1996: 19). Scepticismul istoric spenglerian are ecouri considerabile în Spațiul mioritic, însă cele mai puternice înrâuriri le manifestă asupra lui Cioran, publicistica stilistului din Rășinari probând faptul că sonora concepție a lui Splengler axată pe „opoziția polară dintre cultură și civilizație "și pe distincția dintre „conștiința europeană și cea națională” se bucura de o rodnică asimilare în gândirea sa ${ }^{6}$.

Emil Cioran dă glas răvrătirilor sale metafizice învăluite în mantaua lirismului și în irizațiile aforistice. El atribuie culturilor minore și, implicit, celei românești, eticheta de producătoare ale unei subistorii, evidențiindu-le inferioritatea în fața hegemoniei zdrobitoare a marilor culturi. Derizoratul inabilității de a influența alte culturi și tendința

\footnotetext{
$\overline{\text { 5. În Căderea in timp }}$, Cioran declamă, în pură descendență spengleriană: „A viețui numai ca popor înseamnă a înregistra istoria; ca națiune, te înregistrează istoria. Colectivitățile umane care au rămas numai popoare n-au trecut mult peste biologie" (Cioran, 2002: 53-54).

6. Un alt articol semnat de Emil Cioran, „Între conștiința europeană și cea națională”, publicat ulterior și în volumul Revelațiile durerii, îl numește pe Spengler „ultimul care a dat lovitura de grație Europei, căreia nu i-a reunoscut, pentru viitor, decât o solidaritate în amurg, o unitate in prăbușire”(Cioran, 1990: 179).
} 
nefericită de a rămâne prinse în confiniile etnicului sunt reclamate cu vehemența cunoscută: "Marşul marilor culturi în istorie seamănă, de aceea, unei fatalități; căci nimic nu le poate opri de la pornirea lor de a se afirma şi individualiza, de a impune stilul lor de viaţă altora şi de a robi totul fascinației lor violente. Existînd relativ puţine culturi mari, numărul fenomenelor istorice este fatal limitat. Atîtea popoare şi-au ratat soarta neputîndu-se împlini spiritual şi politic, rămînînd condamnate la etnic, la mărginirile etnicului, incapabile să devină naţiuni şi să creeze o cultură!’ (Cioran, 1990: 13). Din rezonanțele sumbre și vindicative slujite cu sagacitate de instrumentele stilului cu reflexe apodictice rezultă, după expresia Martei Petreu, „un portret violent, expresionist, care îl plasează pe Cioran în aripa extrem de critică a românologilor" (Petreu, 2011: 237). Colecția posibilă de fenomene istorice este condiționată de numărul și capacitățile modelatoare ale culturilor mari, calcul filosofic ce exclude, prin inferență, participarea culturilor minore la producerea evenimentelor semnificative. Epifenomenul neglijabil al angajării culturii românești în dinamica istoriei este susținut prin observații și argumente desprinse din zodia spengleriană, colorate de izbucniri retorice ${ }^{7}$. Scepticismului filosofiei istoriei și proeminenta descendență spengleriană cunosc în Schimbarea la față a României un ascendent notabil, lucrarea fiind înțesată de referiri și nuclee conceptuale preluate din Declinul Occidentului. „Viziunea macrosopică a istoriei”, proferată de Cioran, corespunde "morfologiei istoriei" popularizată de Spengler, asemenea existenței unui număr redus de culturi majore, a interesului pentru istorie ca reflexie a spiritualității decadente sau a ideii de subdiviziune a procesului istoric, relativ prin esența sa, în sub-istorie, istorie și post-istorie. Profilul brutal al devenirii culturii românești este construit prin adoptarea acestor categorii, adaptate gândirii cioraniene. România este aruncată în clasa periferică a culturilor mici, circumstanță explicată prin natura sa deficitară, deplasând accentul de pe

7. În Schimbarea la față a României Cioran amendează patetic situația jalnică de a ne fi așteptat soarta istorică întârziată timp de o mie de ani, urmând recognoscibilele supoziții spengleriene care decretau un mileniu drept durata de viață a unei culturi mari: „Doamne! ce vom fi făcut o mie de ani?! Toată viața noastră de un secol încoace nu este decât procesul prin care am ajuns să ne dăm seama că $n$-am făcut nimic... Comparația cu ce s-a indeplinit în alte părţi ne-a revelat neantul trecutului propriu şi inexistența culturii noastre. Dacă Ortega y Gasset găseşte că Spania, din inceputurile ei, trăieşte o continuă decadenţă, atunci ce mai putem spune despre România, care s-a născut la viața istorică pe cînd ceilalţi începeau să se stingăa? O mie de ani s-a făcut istoria peste noi: o mie de ani de subistorie" (Cioran, 1990: 39). 
supralicitatul context istoric fatidic pe structura psihologică a poporului: „Deficiențele actuale ale poporului român nu sunt produsul «istoriei» sale; ci istoria aceasta este produsul unor deficiențe psihologice structurale" (Cioran, 1990: 60). Această aserțiune îl separă tranșant de viziunea blagiană, care pune pe seama mișcărilor istoriei paralelismul românesc, materializat în "boicotul istoriei”.

Emil Cioran își manifestă și autonomia față de sistemul teoretic al lui Spengler, operând câteva dezarticulări semantice, semn că puterea propriilor convingeri rivaliza cu popularitatea ideilor filosofului german. Spengler individualizează fiecare cultură, introduce atributul unicității, în timp ce eseistul preferă taxonomii cantitative, valorificând excesiv categoriile de culturi mari, mici și intermediare. Cioran mai respinge fatalismul și perspectiva organicistă, preferate însă de Lucian Blaga, și întrebuințează ideea „saltului istoric”. De asemenea, filonul scepticismului istoric nu își are locul decât în substanța culturilor mari, mediul românesc fiind incompatibil cu acesta ${ }^{8}$. Nu putem ignora că ipotezele care înconjoară declinul istoric al omului sunt elaborate de Emil Cioran tot sub influența covârșitoare a premiselor lui Spengler despre declinul Occidentului, la care se adaugă și improvizațiile memoriei sale afective și subiectivitatea sa deformatoare, după cum demonstrează și Ioan Costea în Sfârșitul istoriei după Cioran: „Foarte probabil că la aceasta, dincolo de ideea lui Spengler, a contribuit hotărâtor "spectacolul deringoladei» văzută din interior și al cărui martor s-a constituit prin scrisul său. De altfel, într-o scrisoare din 1976 către Wolf Aichelburg, el recunoaște în acest sens: "Din toată opera spengleriană n-o să rămână decât un titlu, dar importanța lui va crește cu fiecare zi. Mărturisesc că sunt fericit să pot observa îndeaproape spectacolul unui atât de evident Untergang”" (Cristea, 2009: 42). Schimbarea la față a României rămâne unul dintre cele mai sistematice volume semnate de Cioran, iar conținuturile sale explorează cu aplomb fundamentele spengleriene ale filosofiei istoriei și culturii, grefându-le pe proiecțiile propriilor orizonturi de referință metafizică. Discontinuitatea proceselor istoriei, dihotomia cultură mare - cultură mică și vârstele civilizaționale străbat această analiză acidă și folosesc la determinarea fizionomiei și ontologiei spațiului românesc. Cartea oferă totodată o replică soluției blagiene de reprezentare

8. „Scepticismul este extrem de interesant ca pauză în cultură, ca recreaţie a spiritului după epocile constructive. El exprimă atunci dorinţa unei respiraţii iresponsabile a spiritului, a unei complăceri în propria lui inutilitate. Dar este întristător scepticismul teluric şi subteran al României" (Cioran, 1990: 70). 
idealistă a devenirii culturii române.

\section{Concluzii}

Cele două spectre prezentate adună reflecții disparate și dispersate asupra devenirii și istoricității românești, fiind articulate sistemic de Lucian Blaga și Emil Cioran, pe un fundal morfologic spenglerian, din care fiecare preia și resemantizează concepte pentru a se armoniza cu liniile impuse de viziunile proprii. În acord cu conformația intelectuală și cu cea metafizică a autorilor, Spațiul mioritic și Schimbarea la față a României se plasează într-un incitant dialog, tratând paralelismul istoric românesc nu numai printr-o opoziție tăioasă care să solicite excluderea definitivă a celeilalte perspective, ci mai ales printr-o surprinzătoare alinere filosofică, justificată prin înrâuririle comune și prin cordialitatea relațiilor dintre cei doi scriitori. Simultaneitatea antinomică este contrabalansată de abundența unor consistente locuri comune, precum distincția cultură mică-cultură mare, încadrarea României în categoria culturilor mici, ideea vârstelor și destinului unei culturi, nivelurile istoriei, adoptarea categoriilor spațiale și temporale în descendență spengleriană. Diferențele de opinie constau în descrierea dinamicii cauzale și în considerarea elementului arbitrarietății istorice ca factor-cheie în evoluția unui popor. Lucian Blaga va pune retragerea românilor din istorie pe seama unei condiționări exterioare, imprevizibile, atribuind-o retragerii romanilor din Dacia și năvălirii popoarelor migratoare, în timp ce Emil Cioran va opta pentru o explicație bazată pe factori interiori, înscriși în codul psihologiei autohtone, marcată de o substanță spirituală deficitară și de lipsa instinctului de a crea istorie. In consecință, retragerea culturii române într-o sub-istorie va fi privită cu compătimire de către Blaga și blamată cu violență de către Cioran, uzând de strategiile stilistice caracteristice fiecăruia dintre gânditori. 


\section{Bibliography:}

Blaga, Lucian, Luntrea lui Caron, București, Editura Humanitas, 2013.

Blaga, Lucian, Trilogia Cunoașterii, București, Editura Humanitas, 2013.

Blaga, Lucian, Trilogia Culturii, București, Editura pentru Literatură Universală, 1969.

Blaga, Lucian, Corespondență (A-F), Cluj-Napoca, Editura Dacia, 1989.

Cioran, Emil, Caiete, București, Editura Humanitas, 2016.

Cioran, Emil, Schimbarea la față a României, București, Editura Humanitas, 1990.

Cioran, Emil, Singurătate și destin, București, Editura Humanitas, 1991.

Cioran, Emil, Sfârșitul care începe, București, Editura Humanitas, , 1994.

Cioran, Emil, Exerciții de admirație, București, Editura Humanitas, 2002.

Cioran, Emil, Căderea în timp, București, Editura Humanitas, 2002.

Cioran, Emil, Revelațiile durerii, Cluj-Napoca, Editura Echinox, 1990.

Cioran, Emil, Scrisori către cei de-acasă, București, Editura Humanitas, 1995.

Ciocârlie, Livius, Caietele lui Cioran, București, Editura Humanitas, 2007.

Costea, Ioan, Sfârșitul istoriei după Cioran, Editura Ideea Europeană, 2009.

Sasu, Aurel, Politică și Cultură, Cluj-Napoca, Editura Școala Ardeleană, 2016.

Simion, Eugen, Cioran: o mitologie a nedesăvârşirii, Editura Tracus Arte, 2014.

Spengler, Oswald, Declinul Occidentului, Craiova, Editura Beladi, 1996.

Spengler, Oswald, Omul și tehnica, Oradea, Editura Aion, 1996.

Gregori, Ilina, Cioran. Sugestii pentru o biografie imposibilă, București, Editura Humanitas, 2012.

Modreanu, Simona, Cioran, Iași, Editura Junimea, 2005.

Necul, Ionel, Cioran, scepticul nemântuit, Editura Demiurg, 1995.

Petreu, Marta, Cioran sau un trecut deocheat, Iași, Editura Polirom, 2001. 